\title{
ALFABETIZAÇÃO CIENTÍFICA E TECNOLÓGICA NA VISÃO DE ALUNOS ENCARCERADOS
}

\author{
ANTONELLA CARVALHO DE OLIVEIRA \\ DAMARIS BERALDI GODOY LEITE \\ ROSEMARI MONTEIRO CASTILHO FOgGIATTO SILVEIRA \\ ANTONIO CARLOS FRASSON \\ Universidade Tecnológica Federal do Paraná - Campus Ponta Grossa \\ Ponta Grossa, Paraná, Brasil \\ E-mail: antonella_0611@hotmail.com,damgodoy@hotmail.com, castilho@utfpr.edu.br, \\ acfrasson@utfpr.edu.br
}

\section{RESUMO:}

O presente pesquisa analisa a alfabetização científica tecnológica (ACT) no ensino médio, sob a ótica de alunos privados de liberdade, articulando os conceitos de educação no sistema prisional e CTS. As discussões se apoiam em autores da atualidade, bem como clássicos da área, portanto, a pesquisa tem cunho bibliográfico. É exploratória porque embora a ACT seja constante alvo de pesquisas no Brasil, são parcos os trabalhos que aliam essas concepções à educação no sistema carcerário. O procedimento técnico adotado foi o estudo de caso. Os dados foram obtidos mediante aplicação de questionário a 43 alunos privados de liberdade, egressos do ensino médio de um Centro Estadual de Educação Básica para Jovens e Adultos da rede pública do Paraná, localizado dentro de uma unidade penal. Todos os alunos assinaram o termo de consentimento livre e esclarecido. Convém elucidar que embora os alunos sejam egressos do ensino médio, os mesmos permanecem presos em regime fechado e/ou semiaberto na referida unidade penal. A hipótese elaborada para o estudo partiu da premissa de que os alunos privados de liberdade não são alfabetizados cientificamente em função das limitações impostas pelo sistema carcerário, o que vem corroborar com a origem humilde e ausência de escolarização em idade adequada da totalidade dos alunos pesquisados.

\section{PALAVRAS-CHAVE:}

CTS, sistema prisional, educação de jovens e adultos, educação prisional, educação básica.

\section{SCIENTIFIC AND TECHNOLOGICAL LITERACY IN THE VISION OF IMPRISONED STUDENTS}

\section{ABSTRACT:}

This research analyzes the technological scientific literacy in high school, from the perspective of private students of freedom, articulating the concepts of education in prison and science technology and society system. Discussions are supported on the currently authors, such as the classics of the area, so the research has bibliographic nature. It is exploratory because although the Scientific and technological literacy is constant subject of research in Brazil are scarce jobs that 
combine these concepts to education in the prison system. The technical procedure adopted was the case study. The data were obtained by questionnaire to 43 private students of freedom, high school graduates of a State Center for Basic Education for Youth and Adults Paraná public network located within a penal unit. All students signed by free and informed consent. It should be clear that even though students are high school graduates, they remain stuck in closed system and / or semi-open in the already mencioned criminal unit. The hypothesis developed to the study started with the premise that private students of freedom are not scientifically literate due to the limitations imposed by the prison system, which corroborates with the humble origins and lack of schooling at the appropriate age of all students surveyed.

\section{KEYWORDS:}

Science Technology and Society, prisional education, adult education, basic education, prisional education.

\section{INTRODUÇÃO}

A educação é um direito humano subjetivo, previsto em diferentes instrumentos legais e sintetizado no Art. 205 da Constituição Federal (CF) "A educação, direito de todos e dever do estado e da família, será promovida e incentivada com a colaboração da sociedade, visando o pleno desenvolvimento da pessoa, seu preparo para o exercício da cidadania e a sua qualificação para o trabalho" (BRASIL, 1988, p. 34). Os incisos I e II do Art. 208 da CF, estabelecem o dever do estado na garantia do ensino, assegurando, inclusive, "Ensino fundamental, obrigatório e gratuito, inclusive para os que a ele não tiveram acesso na idade própria" e "Progressiva extensão da obrigatoriedade e gratuidade ao ensino médio" (BRASIL, 1988, p. 35).

A Lei Federal de Execução Penal Brasileira ${ }^{1}$ (LEP), marco legal mais importante na área, determina expressamente que os estabelecimentos penais ofereçam assistência educacional aos detentos. Nos artigos 17 e 18-A (BRASIL, 1984) essa assistência é definida a partir dos seguintes parâmetros: (a) ensino fundamental obrigatório; (b) implantação do ensino médio, [...], em obediência ao preceito constitucional de sua universalização ${ }^{2}$ e (c) oferta de educação na modalidade de Educação de Jovens e Adultos (EJA).

A fim de operacionalizar o texto da LEP, o Conselho Nacional de Política Criminal e Penitenciária, por meio da Resolução CNPCP № 14, de 11 de novembro de 1994, editou as regras mínimas para o tratamento do preso no Brasil, em consonância com decisões tomadas em congressos internacionais sobre justiça penal.

\footnotetext{
${ }^{1}$ Lei Federal № 7.210, de 11 de julho de 1984. Institui a Lei de Execução Penal no âmbito do território nacional.

2 Lei Federal № 13.163 , de 9 de setembro de 2015. Modifica a Lei Federal № 7.210 , de 11 de julho de 1984 - Lei de Execução Penal, para instituir o ensino médio nas penitenciárias.
} 
A regulamentação da oferta educacional no sistema penitenciário do Paraná decorre das diretrizes nacionais para a oferta da educação em estabelecimentos penais, aprovadas pela Resolução CNPCP № 3, de 11 de março de 2009, do Conselho Nacional de Política Criminal e Penitenciária, que foram homologadas pelo Ministério da Educação por meio da Resolução CNE № 2, de 19 de maio de 2010, do Conselho Nacional de Educação. A Constituição do Estado do Paraná, no Art. 239, também determina que "O estado promoverá a assistência a homens e mulheres internos e egressos do sistema penitenciário, inclusive aos albergados, visando à sua reintegração à sociedade" (PARANÁ, 1989).

A formação dos sujeitos na EJA, fundamentada no princípio da aprendizagem ao longo da vida, deve comprometer-se com a aquisição de conhecimentos, o desenvolvimento de capacidades, habilidades, competências e valores necessários ao exercício e ampliação de seus direitos e controle de seus destinos, possibilitando o alcance da equidade e da inclusão social, para a redução da pobreza e a construção de uma sociedade justa, solidária e sustentável. Desta forma, a EJA cumprirá suas funções:

i. Reparadora: permitindo a entrada do indivíduo privado de liberdade no circuito dos direitos civis pela restauração de um direito negado, o direito a uma escola de qualidade e o reconhecimento da igualdade ontológica entre todo e qualquer ser humano;

ii. Equalizadora: reinserindo os encarcerados no sistema educacional, seja porque tiveram uma interrupção forçada pela repetência, pela evasão, pelas desiguais oportunidades de permanência ou outras condições adversas. Esta ação da EJA deve ser vista como reparação corretiva, ainda que tardia, de estruturas arcaicas, possibilitando aos indivíduos em situação de cárcere, inserções no mundo do trabalho, na vida social, nos espaços da estética e na abertura dos canais de participação, quando em liberdade;

iii. Qualificadora: considerando o caráter incompleto de todo ser humano cujo potencial de desenvolvimento e de adequação pode se atualizar em quadros escolares ou não escolares, em espaços de liberdade ou não.

O olhar sobre o ensino deve levar a uma profunda reflexão sobre a realidade, questionando procedimentos, formas de avaliar, agir e interagir, possibilitando trazer os problemas e discuti-los com atitude politizada e, sobretudo, democrática, em um contexto científico e social. Entretanto, é necessário equacionar, da melhor forma possível, os recursos humanos, financeiros, técnicos, didáticos e físicos disponíveis, para garantir tempos, espaços, situações de interação, formas de organização da aprendizagem e de inserção de conhecimentos, competências e valores, formando um ambiente propício para a alfabetização científica e tecnológica (ACT). 
Vale ressaltar que é preciso avaliar a ciência e a tecnologia como forma de vida e entendê-las dentro de um tripé fundamental: como instrumentos, como organização e como cultura (BAZZO, 2014, p. 186). Nesse sentido, destaca-se que é senso comum defender a educação e o trabalho como fatores determinantes para futura reinserção do preso na vida social e no mercado de trabalho. As atividades educativas ainda que não atinjam todos os apenados, são, sem dúvida, necessárias dentro das unidades penais e devem ser estimuladas e difundidas de modo a consolidar essa prática.

A educação, aqui, não deve ser entendida apenas do ponto de vista da certificação escolar, mas como um programa sistemático de práticas educacionais, que auxiliem o indivíduo a ter experiências mais amplas e mais ricas de interação social, bem como, através do contexto CTS possa emancipar-se e compreender as emaranhadas relações do mundo atual. Diante disto, entendemos que conhecer as relações sociais do desenvolvimento científico e tecnológico é um instrumento fundamental para que o homem construa patamares cada vez mais elevados de compreensão do mundo e para que seja capaz de realizar operações mentais mais elaboradas, críticas e reflexivas em condições de tomar decisões mais conscientes em relação às questões científicas e tecnológicas, visando à sustentabilidade. A partir do exposto, foi demarcado o seguinte objetivo geral para esta pesquisa: Analisar a ACT no ensino médio, sob a ótica de alunos privados de liberdade, articulando os conceitos de educação no sistema prisional e CTS.

\section{METOdOLOGIA}

Pesquisa aplicada, quantitativa, exploratória e um estudo de caso, realizado através de aplicação de questionário, com dez questões fechadas, a 43 alunos privados de liberdade e egressos do ensino médio de um Centro Estadual de Educação Básica para Jovens e Adultos (CEEBJA) da Rede Pública do Paraná, localizado dentro de uma unidade penal. Todos os alunos assinaram o termo de consentimento livre e esclarecido. A hipótese elaborada para o estudo partiu da premissa de que os alunos privados de liberdade não são alfabetizados cientificamente em função das limitações impostas pelo sistema carcerário.

O questionário é uma adaptação de Silveira (2007) e Aikenhead, Ryan e Fleming (1989), estes últimos desenvolveram um instrumento conhecido como Views on Science-Technology-Society Instrument (VOSTS) cuja finalidade é investigar qual a representação que os estudantes jovens têm sobre CTS. Para o levantamento de informações pessoais, com a finalidade de traçar o perfil dos respondentes, foram consultadas as fichas de matrículas dos alunos que constituem a população do presente estudo. 
Barros e Lehfeld (2012) e Hoppen (1996) alertam que quando o pesquisador utiliza um instrumento de coleta de dados não validado, o mesmo deve ser submetido à pré-teste e a validação. Neste sentido, entendem que um grupo de especialistas pode dar assistência ao pesquisador no desenvolvimento dos enunciados. Para operacionalização da validação foram convidados quatro especialistas na área de CTS da Universidade Tecnológica Federal do Paraná, a fim de que dessem parecer sobre o conteúdo. O pré-teste foi realizado com $10 \%$ da população investigada, conforme sugerem Lakatos e Marconi (2010). As sugestões de alteração provindas da validação e do pré-teste e julgadas pertinentes pelos pesquisadores foram acatadas.

Para a coleta de dados, cada pergunta do questionário foi fotocopiada em letra caixa alta, fonte 16, espaçamento duplo e em folha individual, dez folhas para cada questionário/aluno. Após o consentimento do aluno apenado em participar da pesquisa, era disposta a pergunta à frente do mesmo para que ele pudesse ler e em seguida indicar a alternativa escolhida, por questões inerentes à unidade penal os alunos que participaram da pesquisa não puderam portar lápis ou caneta, então a alternativa sempre era marcada por uma das pesquisadoras.

$\mathrm{Na}$ análise dos dados e tendo em vista que a abordagem do problema tem característica exploratória, procedeu-se a:

- Organização e descrição dos dados/ conteúdos brutos;

- Redução dos dados;

- Interpretação dos dados pelas categorias teóricas de análise.

Levando em consideração que a hipótese do estudo aponta que os alunos apenados não são alfabetizados cientificamente em função das limitações impostas pelo sistema carcerário, as três categorias de análise foram assim dispostas:

- Grupo A: respostas que contenham componentes relevantes para a aprovação da hipótese;

- Grupo B: respostas que contenham componentes considerados adicionais e/ou intervenientes para a comprovação da hipótese;

- Grupo C: respostas que contenham dados considerados irrelevantes para a comprovação da hipótese ou mesmo que a refutem.

A análise dos dados, fruto da pesquisa, poderá integrar as políticas públicas de educação no sistema prisional, com vistas a instrumentalizar os alunos privados de liberdade para a reinserção na sociedade. Ao escolhermos a referida unidade para avaliar a ACT, buscou-se alcançar a compreensão de um universo maior. Embora o processo ensino aprendizagem em unidades prisionais localizadas em outros estados 


\section{DEDebates \\ em Educação Científica e Tecnológica \\ ISSN - 2236-2150 (Eletrônica)}

não ocorra exatamente igual ao estado do Paraná, o estudo ora apresentado pode nos oferecer uma ideia aproximada de outras realidades. 


\section{RESULTADOS E DisCUSSÃO}

Para o levantamento de informações pessoais, foram consultadas as fichas de matrículas dos alunos que constituem a população do presente estudo. O perfil do público pesquisado é composto por jovens (entre 18 e 35 anos), do sexo masculino (100\%), pobres (95\%), afrodescendentes (87\%) e com baixa $(72 \%)$ ou nenhuma escolaridade (28\%). Em sua maioria estavam desempregados e/ou associados ao narcotráfico quando foram presos. Este perfil de aluno não difere significativa das outras regiões do Brasil. Conforme exposto na metodologia e considerando a hipótese formulada para a pesquisa, a análise e discussão dos dados serão apresentadas conforme as três categorias de análise ora delimitadas.

\subsection{Respostas qUe CONFIRMAM a hipótese da PESQUisa}

Na assertiva "1. Para você o que é ciência?" 23 pesquisados responderam de forma a comprovar a hipótese da pesquisa, sete com questões adicionais e nenhum com questões que refutassem a hipótese elaborada. Camargo et al., (2011), verificou esta mesma especificidade em seus estudos, guardada as proporções do público diferenciado, o pesquisador também foi capaz de comprovar a mesma hipótese com uso de instrumento similar. Cada cidadão tem seus valores e posturas sobre as questões científico-tecnológicas. Por isso, uma adequada participação na tomada de decisões que envolvem ciência e tecnologia deve passar por uma negociação (PINHEIRO, SILVEIRA e BAZZO, 2007, p. 73).

Quanto à questão "2. Em sua opinião, qual a relação entre a tecnologia, ciência e sociedade?" 23 alunos dos 43 entrevistados confirmaram a hipótese de que têm baixa ACT, tendo uma leitura de mundo dificultada pelo escasso entendimento do tema "a ciência como uma linguagem para facilitar nossa leitura do mundo" (CHASSOT, 2010, p. 61).

Quanto à influência que o desenvolvimento científico e tecnológico exerce sobre a sociedade, questão "4. Você pensa que o desenvolvimento científico e tecnológico exerce algum tipo de influência sobre a sociedade?", 23 alunos confirmam a hipótese da pesquisa, sendo que 11 alunos responderam que "Não, porque a tecnologia avança tão rapidamente que a sociedade não acompanha o seu desenvo/vimento", quatro alunos estão dentro das hipóteses adicionais e 20 comprovaram a mesma, prevalecendo à ideia de que a ciência é neutra, herança de um período histórico recente, amplamente discutido em trabalhos de Auler (2002), Gordillo e Galbarte (2002) e Carletto (2011).

Sobre a crença de uma sociedade funcionando sem ciência e sem tecnologia, questão "5. Você acredita que nossa sociedade poderia funcionar sem ciência e sem tecnologia?" 25\% dos entrevistados optou pela alternativa "Sim, porque tudo é possível", o que denota total falta de entendimento do que é CTS. Os alunos, talvez 
em função de sua condição de apenados, nem sempre conseguem elaborar um raciocínio completo para algo em que acreditam, ao invés disto optam para o mais fácil, "tudo é possível". E os outros $25 \%$ alegam não saber o suficiente sobre o tema para fazer esta escolha. Fica claro pelos achados que, ao menos nesta questão, os alunos representam deter pouca compreensão sobre CTS.

A última questão do instrumento de coleta de dados inquiriu a opinião dos pesquisados sobre política, economia, cultura, sociedade e ambiente e se os mesmos poderiam influenciar o desenvolvimento científico e tecnológico: "10. Em sua opinião, fatores como: política, economia, cultura, sociedade e ambiente podem influenciar o desenvolvimento científico e tecnológico? Se sim: O que acha dessa influência? Como vê essa influência? Se não: Por que acha isso?" 19 alunos responderam que sim, que os fatores elencados influenciam no desenvolvimento científico e 24 acreditam que não. Este resultado corrobora com a hipótese da pesquisa. Abaixo a transcrição das falas dos alunos que não acreditam que os fatores influenciam o desenvolvimento científico e tecnológico e que deram sua justificativa. Dos 24 alunos, designados aqui pela sigla APL (alunos privados de liberdade), apenas sete justificaram:

APL 7: Não sei explicar;

APL 10: Tá aqui na minha cabeça só não sei dizer;

APL 13: Ninguém tá nem aí para a cultura do povo, eu sou do funk e ninguém liga para o que achamos...;

APL 20: O povo é pobre, miserável, passa fome.Ninguém liga;

APL 21: Meus filhos tem computador, minha mulher comprou com a mesada, acho que é importante. Eles já sabem usar a internet;

APL 25: Sei lá, muito "fofo" explicar isso;

APL 38: Ah não sei nada não, mas acho que poluir o ambiente não é legal.

As falas dos entrevistados demonstram visões diferenciadas da CTS e como isso influência em sua vida e de suas famílias. É possível constatar que alguns alunos utilizaram o espaço para reivindicar questões como fome, cultura e a pobreza de modo geral. Existe uma ânsia em serem ouvidos. Há também o apelo do que "não sabe explicar" e o mais interessante foi à justificativa do entrevistado 25, pois "fofo" é uma gíria de unidade prisional, que não está catalogada, mas significa algo que não funciona bem. 


\subsection{RESPOSTAS ADICIONAIS E/OU INTERVENIENTES PARA A COMPROVAÇÃO DA HIPÓTESE}

Em relação à questão de pesquisa "7. O que você aprende nas aulas de Ciências (física, química, biologia) te ajuda a resolver problemas práticos do seu dia a dia?" 25 alunos ofereceram respostas que permitem compreender que eles detêm algum entendimento sobre CTS e que as relações podem ser ampliadas de acordo com o meio em que estão inseridos. 16 alunos responderam que "Às vezes me ajuda a resolver problemas ou tomar decisões sobre algumas coisas, como cozinhar alimentos saudáveis, por exemplo." Nove alunos assinalaram a questão "Sim, me ajuda a resolver alguns problemas na minha vida diária". Esses dados vão ao encontro dos achados de Pinheiro et al., (2007) realizado com alunos do ensino médio.

Torna-se necessário que a população possa, além de ter acesso às informações sobre o desenvolvimento científico-tecnológico, ter também condições de avaliar e participar das decisões que venham a atingir o meio onde vive (PINHEIRO; SILVEIRA; BAZZO, 2007, p. 72).

As propostas para o ensino do cidadão precisam levar em conta os conhecimentos prévios dos alunos, o que pode ser feito mediante a contextualização dos temas sociais, na qual se solicita a opinião dos alunos a respeito do problema que o tema apresenta, mesmo antes de ser discutido do ponto de vista do conhecimento (Matemática, Física, Química, Biologia). Trabalhar com os alunos nesse sentido não se restringe a uma simples adequação de fatos descontextualizados da realidade, mas implica a redefinição de temas sociais próprios ao contexto nacional, local, ou adaptado à problemática brasileira (PINHEIRO; SILVEIRA; BAZZO, 2007, p. 80).

Os pressupostos adotados pelo estado do Paraná, no que tange a educação formal é a tendência histórico crítico social dos conteúdos, o que deveria levar a uma taxa elevada entre aprendizagem e aplicação prática, pois essa postura epistemológica se aproxima do movimento CTS, que amplia a visão e leitura de mundo do aluno e do cidadão, fazendo traçar paralelos entre o aprendido e a realidade, o presente e o futuro, as ações e as reações, ou seja, transforma esse educando em um sujeito pensante e que faz uma melhor leitura de mundo. Os dados coletados não visavam essa análise, mas aparentemente pode-se afirmar que estes alunos estão neste processo de construção.

A última questão questionou: "9. A religião de um cientista faz alguma diferença para as descobertas científicas que ele faz?" Nove alunos optaram por "Depende da religião e da força da visão religiosa do cientista". Os demais alunos 
dividiram-se entre "A religião pode afetar o que os cientistas fazem, ou quais os problemas que eles escolhem para trabalhar" e "Eu não entendo". Provavelmente estas respostas carregam em seu cerne o mito de que religião e ciência não se misturam ou têm significados antagônicos. O conhecimento que os entrevistados possuem ainda não é capaz de transpassar essa realidade aparente.

\subsection{Respostas que a REFUtAM A hipótese da PESQUisa}

$\mathrm{Na}$ questão "3. Como você percebe a evolução das novas tecnologias para o desenvolvimento humano?" 12 alunos marcaram a alternativa "Nosso pensamento cotidiano é influenciado pela inovação tecnológica porque as inovações nos oferecem novas ideias do que fazer e isso afeta o desenvolvimento humano"; dez marcaram que "As inovações tecnológicas influenciam nosso desenvolvimento principalmente quando ampliam o nosso modo de agir e pensar a vida" e seis marcaram a resposta "A relação é bem grande, porque usamos cotidianamente os produtos que são frutos de inovações tecnológicas, tais como, computadores, microondas, máquinas de lavar roupa e etc.". As alternativas marcadas pelos alunos corroboram com Bazzo (2014, p. 111) quando afirma que a educação científica e tecnológica deve servir de modo que os processos beneficiem a humanidade.

Ao responderem a assertiva de número "8. Você acredita que os países mais poderosos do mundo têm força militar porque tem ciência e tecnologia superiores?" 13 alunos responderam que "A força militar depende em parte de ciência e tecnologia e, em parte, da decisão do governo para desenvolver armas e aumentar seu contingente de militares" e nove "Sim, porque quanto mais desenvolvida a ciência e tecnologia, mais modernas, precisas e destrutivas são as armas". Ficou claro aos pesquisadores que essa foi à questão que mais atraiu os entrevistados, alguns quiseram debater sobre força militar e armas. Portanto, a partir desta questão pode-se compreender que os alunos abarcam, ainda que somente quando se fala em armas, os conceitos de ciência e tecnologia, o que vai ao encontro da aprendizagem significativa, pois os apenados demonstram entender que a ciência e a tecnologia são componentes diferenciadores na força militar de um país.

\section{CONSIDERAÇÕES FINAIS}

A partir da análise e discussão dos dados foi confirmada a hipótese de que os alunos privados de liberdade, egressos do ensino médio, não são alfabetizados cientificamente no contexto CTS, pois, das dez questões aplicadas, seis remeteram a categoria de análise aqui denominada "grupo A" (respostas que confirmam a hipótese da pesquisa).

Revisitando atentamente a legislação pertinente à educação no contexto prisional e a LEP, verifica-se que há grande expectativa que a educação possa ser um 
agente transformador no cárcere, que possibilite ao aluno apenado uma nova visão de mundo, outras expectativas em relação ao seu futuro e até mesmo possa promover sua ressocialização. Entretanto, o cárcere, ao avesso de corrigir, produz delinquentes. Encarceram seres humanos em cubículos, impondo-lhes por vezes trabalhos inúteis, isso não é pensar o sujeito social, é "inventar" um ambiente que contradiz a natureza humana, além de baldia e perigosa medida. Desta forma não é possível educar alguém, pois a disciplina aplicada no cárcere, constituída de poder, controle e desigualdade social recai sobre o sujeito histórico.

À tona desta situação, cultivamos a ambiciosa (e ingênua) esperança que os alunos apenados estejam inseridos no contexto CTS para sua ressocialização, dentro de uma concepção libertadora de educação. Estes pressupostos, em teoria, encontram no enfoque CTS local fecundo para suas aspirações, mas na prática, deixa o apenado mais distante da realidade "do lado de cá".

Concluímos que, assim como a escolarização no Brasil é frágil e muitos são os fatores que contribuem para esse fato, no sistema carcerário não é diferente, mas aqui a lógica é simples e clara, pois é pautada em um sistema de relação de poder em que o fracasso é parte essencial do "trabalho" da prisão.

\section{REFERÊNCIAS}

AULER, D. Interações entre ciência-tecnologia-sociedade no contexto da formação de professores de ciências. Florianópolis, 248 p., 2002. Tese (Doutorado) - UFSC.

BARROS, A. J. da S.; LEHFELD, N. A. de S. Projeto de pesquisa: propostas metodológicas. 21 ed. Rio de Janeiro: Vozes, 2012.

BAZZO, W. A. Ciência, tecnologia e sociedade: e o contexto da educação tecnológica. 4 ed. Florianópolis: Ed. da UFSC: 2014.

BRASIL. Lei de Execução Penal. Lei Federal, № 7.210 de 11 de julho de 1984.

BRASIL. Ministério da Educação. Conselho Nacional de Educação. Parecer da Câmara de Educação Básica (CEB), № 11/2000. Brasília, DF, 2000.

BRASIL. Presidência da República. Constituição da República Federativa do Brasil de 1988. Brasília, 1988.

CAMARGO, A. N. B. et al. Alfabetização Científica: a evolução ao longo da formação de licenciados ingressantes, concluintes e de professores de química. Momento. V. 20, N. 2, p. 19-29, 2011.

CARLETTO, M. R. Avaliação de impacto tecnológico: reflexões, fundamentos e práticas. Curitiba: Ed. UTFPR, 2011. 
CHASSOT, A. Alfabetização científica: questões e desafios para a educação. 5. ed. Ijuí: Editora IJUÍ, 2010.

GORDILLO, M.M.; GALBERT, J.C.G. Reflexiones sobre La educacion tecnológica desde El enfoque CTS. Revista Iberoamericana de Educación. Madrid: p. 17-59, 2002.

HOPPEN, N.; LAPOINTE, L.; MOREAU, E. Um guia para avaliação de artigos de pesquisa em sistemas de informação. Revista Eletrônica de Administração. n.3, agosto 1996.

LAKATOS, E.V; MARCONI, M.A. Fundamentos de Metodologia Científica. 7.ed. São Paulo: Atlas, 2010.

PINHEIRO, N. A. M.; SILVEIRA, R. M. C. F.; BAZZO, W. A. Ciência, Tecnologia e Sociedade: a relevância do enfoque CTS para o contexto do Ensino Médio. Ciência e Educação. v. 13, n.1, p.71-84, 2007.

SILVEIRA, R. M. C. F. Inovação tecnológica na visão dos gestores e empreendedores de incubadoras de empresas de base tecnológica do Paraná (IEBT-PR): desafios e perspectivas para a educação tecnológica. Florianópolis, 2007. Tese (Doutorado). UFSC. 